\title{
Perspective
}

\section{Introducing Value-Based Purchasing into TRICARE Reform}

\author{
Susan D. Hosek, Melony E. Sorbero, Grant R. Martsolf, and Ryan Kandrack
}

Do

RICARE, part of the military health system, is the health plan for 6.6 million military beneficiaries in the United States (as of 2014), primarily active-duty and retired per-

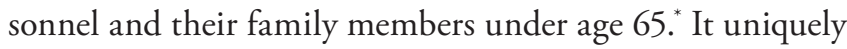
combines a large direct-care system of military treatment facilities (MTFs) with extensive care purchased from the private sector. In 2014, a comprehensive review of this military health system described it as follows:

The Military Health System (MHS) provides a continuum of health services from austere operational environments through remote, fixed medical treatment facilities to major tertiary care medical centers distributed across the United States. Missioncritical aspects of the MHS include the ability to sustain an

\footnotetext{
* In addition, the U.S. Department of Defense (DoD) covers 2.1 million beneficiaries age 65 and older through TRICARE for Life, which supplements Medicare coverage, and 0.3 million Reserve and Guard personnel and their family members through TRICARE Reserve Select.
}

interdependent and self-supporting, responsive health care team. Force Health Protection is the critical support function of the MHS in providing a worldwide deployable defense force. ${ }^{1}$

First developed in the 1980s and implemented in the 1990s, TRICARE adapted the managed care approaches used by civilian employer health plans when redesigning the traditional military health program, which, prior to TRICARE, consisted of the MTFs and civilian care provided through the Civilian Health and Medical Program of the Uniformed Services (CHAMPUS). Thirty years later, employer-sponsored health plans have evolved, but the TRICARE benefit and approach to purchasing civilian care have changed little. DoD and Congress are now considering how to update TRICARE based on experience in civilian health plans while still meeting future military medical requirements. An immediate impetus for reform is the report of the 2015 Military Compensation and Retirement Modernization Commission 
(MCRMC), which cited declining beneficiary access, choice, and value in calling for a major redesign of the benefit. ${ }^{2}$ Rising personnel costs in an era of defense budget cuts are also motivating a thorough look at military health benefits. The MCRMC report recommends replacing TRICARE with private health plans, whereas DoD has proposed more modest changes to TRICARE in its fiscal year (FY) 2017 budget proposal.

This Perspective places TRICARE's current managed care strategy in historical context and describes recent innovations by private insurers and Medicare intended to enhance the value-cost and quality — of the care they purchase for their members. With this movement toward value-based purchasing as background, we consider the MCRMC and DoD proposals for reform and describe an alternative approach that might also be considered. We begin by describing how TRICARE incorporated approaches employed by private and public payers 30 years ago. We then summarize the value-based purchasing approaches being explored today and, finally, consider the options for reforming TRICARE during this period of change in the health marketplace.

\section{Managed Care and TRICARE}

Managed care emerged as a solution to rapidly rising health costs in the 1970s. Before managed care, health plans were described by the services they covered and the beneficiary cost-sharing require-

\section{Employer-sponsored health plans have evolved, but the TRICARE benefit and approach to purchasing civilian care have changed little.}

ments for those services. Beneficiaries could choose to seek care from any physician or hospital, which was paid for each service based on the "usual and customary" charge for that service (feefor-service payments). Managed care introduced three key features designed to strengthen the health plan's role in encouraging costeffective care: ${ }^{3}$

- creation of a provider network that beneficiaries are limited to or given financial incentives to use

- negotiated discounts and new methods of payment for network providers

- utilization management by the health plan through gatekeeping (mandatory referral by a primary care provider for specialty care), prior authorization from the health plan for high-cost care, and ex-post utilization review of care.

Two types of managed care plans emerged. Health maintenance organizations (HMOs) limit beneficiaries to using network providers for almost all of their care. Some HMOs pay providers (or provider groups) a predetermined amount per patient or, in some cases, a salary. HMO beneficiaries are assigned primary care providers, who must provide a referral for specialty care and have overall responsibility for their patients' care. Preferred provider organizations (PPOs) allow beneficiaries full choice of providers but reduce their out-of-pocket cost if they use providers in the PPO's network. PPOs typically pay both network and non-network providers on a fee-for-service basis, but network providers agree to accept discounted rates. Some of the early PPOs experimented with payment methods that shifted some of the financial risk of care to providers. In exchange for limiting provider choice and with the expectation that utilization management would lead to more 
cost-effective care, most managed care plans substantially reduced beneficiary cost-sharing (e.g., lower copayments or coinsurance amounts).

With the implementation of TRICARE, DoD adapted managed care principles to the military system by creating a new HMO option (TRICARE Prime) and reshaping the traditional plan as a PPO (TRICARE Standard/Extra). The HMO is available only in locations with a beneficiary population that is large enough to warrant the effort of establishing a civilian network. In 2013, DoD limited these "Prime service areas" to areas surrounding MTFs or areas near a closed military base. TRICARE provider networks exist in some more areas, but they are not as extensive as the networks maintained by large private health plans.

Active-duty personnel are automatically enrolled in the HMO plan, and other beneficiaries can choose between the HMO and the PPO. The design for the HMO and PPO closely followed designs common in civilian managed care plans in the 1980s. TRICARE reduced beneficiary cost-sharing for use of civilian care; this included a substantial reduction in the HMO option and a more modest reduction in the PPO option in order to induce use of network providers. The MTFs play a major role in the $\mathrm{HMO}$ as the primary care provider for many HMO enrollees; the enrollees that the MTFs cannot accommodate are assigned to network primary care providers. The MTFs also have right of first refusal for specialty referrals for all HMO patients needing the types of care provided in their service areas, although, in practice, MTFs rarely insist on treating patients whose civilian provider has referred them to civilian specialists.

To carry out the significantly more complicated administrative activities associated with managed care, TRICARE issued three regional contracts with civilian third-party administrators (i.e., managed care contractors). The TRICARE program was tested in 1988-1993 and was implemented nationwide in 1996-1998. Implementation was difficult, and it was several years before the program operated as envisioned and HMO enrollment among non-active-duty beneficiaries reached steady-state levels. By 2000, enrollment in TRICARE Prime had reached 3.4 million, or 45 percent of the eligible population in the United States. In 2014, enrollment was 5.0 million, or about two-thirds of the eligible population. Roughly one-third of the beneficiaries in the PPO also have other health insurance coverage, but two-thirds rely on TRICARE as their only source of health coverage. ${ }^{4}$

\section{Decline of Managed Care}

By the time DoD had finished implementing TRICARE, a backlash had developed against civilian managed care plans. Civilian beneficiaries resisted the limitations on provider choice (especially in HMOs), and risk-sharing with providers proved to be problematic in all but large group practices. Physicians objected to having their clinical decisions second-guessed by utilization management programs, and health insurers discovered that the cost savings achieved did not cover the added costs of utilization management. As enrollment in private health plans shifted from restrictive HMOs to the more open-ended PPOs, health plans focused on discounted fee-for-service payment and curtailed or, in some cases, ended their utilization management programs. As a result, $\mathrm{HMO}$ market share in employer plans peaked in 1996 at 31 percent and 


\section{Civilian health plans are currently trying a number of innovative approaches associated with value-based purchasing.}

fell to 14 percent in 2015, while PPO market share had more than doubled to 62 percent by 2015.5

Managed care programs initially led to cost savings as health plans negotiated payment discounts and addressed obvious areas of excess utilization, but costs soon began to rise again. The highdeductible health plan appeared as a way to control costs by shifting some of the cost from the plan to beneficiaries and giving them more reason to consider cost when seeking care. ${ }^{\ddagger}$ Today, these plans account for 24 percent of the market, and traditional fee-for-service plans have all but disappeared. ${ }^{5}$

\section{Recent Trends in Civilian Health Plans}

Civilian health plans are currently trying a number of innovative approaches associated with value-based purchasing, defined as "any purchasing practices aimed at improving the value of health

$\dagger$ Point-of-service health plans are included in the PPO percentage. These plans modify an HMO to cover care from non-network providers at higher cost to the beneficiary.

$\ddagger$ HealthCare.gov defines a high-deductible plan as "[a] plan that features higher deductibles than traditional insurance plans. High deductible health plans (HDHPs) can be combined with a health savings account or a health reimbursement arrangement to allow you to pay for qualified out-of-pocket medical expenses on a pre-tax basis." ${ }^{42}$ care services, where value is a function of both quality and cost." 6 Large employers began to implement value-based purchasing in their employee health plans approximately two decades ago. ${ }^{7}$ The National Business Coalition on Health provides a more complete description of the concept:

Value-based purchasing involves the actions of coalitions, employer purchasers, public sector purchasers, health plans, and individual consumers in making decisions that take into consideration access, price, quality, efficiency, and alignment of incentives. Effective health care services and high performing health care providers are rewarded with improved reputations through public reporting, enhanced payments through differential reimbursements, and increased market share through purchaser, payer, and/or consumer selection. Effective value-based purchasing is an external motivator for providers to lead this re-engineering of health care delivery. ${ }^{8}$

To improve the value of the health care that they purchase, health plans are adopting new patient- and performance-based reimbursement models, which we describe below.

These trends in civilian health plans are occurring at the same time as consolidation among the physician and hospital organizations from which the plans purchase care. Provider organization consolidation and hospital acquisition of physician practices has occurred in waves since the 1990s. The health marketplace is currently experiencing another wave of consolidation, as providers seek greater market power to negotiate with a shrinking number of large insurers and to benefit from perceived economies of scale and scope. ${ }^{9}$ Value-based purchasing further encourages this trend, in the belief that more-integrated provider organizations are better able to coordinate their patients' care, and larger organizations are more able to assume financial risk for cost and quality. As of 
2012, 60 percent of hospitals are in a health system, and hospitalowned physician practices increased from 25 percent of practices in 2004 to 49 percent in $2011 .^{10}$ There is only limited evidence to show whether integrated provider organizations deliver care that is more cost-effective. A review of the literature found some evidence of higher quality in integrated systems but no evidence of lower costs. $^{11}$

\section{Payment Reform}

Payers pursuing value-based purchasing (including Medicare) are experimenting with new payment models. These new payment models are designed to reward providers based on the quality and cost of the care they deliver and, thereby, provide an incentive to coordinate and integrate care across providers and settings. Two of the payment methods are pay for performance and bundled payment; the use of pay for performance is quite common, while the use of bundled payments is more narrowly focused and still experimental.

Pay for Performance. Many payers are expanding their use of pay for performance, a "payment arrangement in which providers are rewarded (via bonuses or larger annual payment updates) or penalized (via reductions in payments) based on meeting preestablished targets for measures of quality and/or cost." 12 Following up on a pay-for-performance demonstration project, Medicare began adjusting hospital reimbursement rates based on quality and cost outcomes in 2013. In 2015, Medicare implemented valuebased purchasing for large physician groups (100 or more physicians); the program expands to groups of ten or more physicians in 2016 and to groups of two or more physicians in 2017. A number of state Medicaid programs have also adopted pay-for-performance approaches. Payers are paying hospitals based on performance across a number of clinical areas, including acute myocardial infarction, diabetes, congestive heart failure, hip and knee arthroplasty, pneumonia, and surgical infections. While this approach seems promising, it has also been met with some challenges. These include financial incentives that are insufficient to actually influence provider behavior, lack of provider buy-in, and lack of consensus on which measures should be rewarded. To address the last two issues, the Centers for Medicare \& Medicaid Services (CMS) recently released a draft Quality Measure Development Plan with a goal of developing common measures that can be used by both public and private payers across delivery systems and that will reduce provider burden. ${ }^{13}$

A 2014 report reviewed 49 studies that assessed the effect of pay for performance on process and quality measures in a group of large interventions. ${ }^{12}$ The studies employed methods that varied in rigor and had mixed results. Those that used stronger research methods were less likely to identify improvements associated with the pay-for-performance programs, and any identified effects were small. Notable findings from the studies to date include the following:

- Several studies of Medicare's hospital pay-for-performance demonstration program found positive but modest quality results. However, hospitals that received a bonus for quality did not consistently continue to improve performance on quality metrics in subsequent years. ${ }^{14}$

- In contrast, the Veterans Health Administration pay-forperformance program was associated with improvements in quality measures for acute coronary syndrome, heart failure, 


\section{Recent evaluations of ACO models, which used a range of methods, have found cost savings.}

and pneumonia, and the improvements were sustained after the program had ended. ${ }^{15}$

- A recent evaluation of the early experience with Medicare's hospital pay-for-performance program found no difference in process of care and patient experience measures after the period of performance between hospitals that did and did not earn the performance bonus. ${ }^{16}$ However, many of these measures have been the focus of quality improvement activities and public reporting for numerous years, leading to increases in quality prior to the implementation of financial incentives.

- There is little consistent evidence on the effect of pay for performance on costs. Two of the stronger studies reported mixed cost effects in physician or physician group settings. ${ }^{1718}$ The Medicare hospital pay-for-performance demonstration had no effect on hospital financial outcomes or Medicare payments. ${ }^{19}$

Bundled Payment. Bundled payment (also called episode-based payment) creates global payment mechanisms that encourage providers to reduce resource use by coordinating and integrating care. Health care providers from across the clinical spectrum (including physicians, hospitals, and post-acute providers) are given a fixed fee for providing care to a patient for an entire treatment episode for a specific condition or intervention. The fixed payment is based on the expected costs for a clinically defined episode or bundle of related health care services. If the providers treating the patient collectively spend less than the fixed fee, they can share the savings. Providers are then incentivized to coordinate care across the continuum. This is a modification of the capitation payment system used earlier by HMOs that focuses the financial risk that providers face on an episode of care for the patient instead of for all care that the patient receives during a year.

Bundled payment is generally used to pay for specialty services that include an inpatient procedure, such as hip and knee arthroplasty or coronary artery bypass surgery, and standard post-acute care. The prevalence of such programs is unknown; various payers, including Medicare, Blue Cross Blue Shield of Tennessee, and private payers who have not yet published the details of their arrangements, currently use bundled payments for at least some patients.

A recent systematic review of the literature related to 19 bundled payment programs showed inconsistency in the size and direction of effects on quality measures (e.g., mortality rates, readmission rates, adherence to clinical process measures, patient satisfaction). ${ }^{20}$ However, all of the programs showed declines of up to 10 percent on spending and utilization. Early feedback from 27 academic medical centers participating in a Center for Medicare and Medicaid Innovation bundled payment initiative were mixed, with cost savings for some conditions and losses for other conditions. ${ }^{21}$

\section{Accountable Care Organizations}

Complementing these payment methods is an increasingly common care delivery model, the accountable care organization (ACO). ACOs combine some level of provider integration with new pay- 
ment models in an effort to improve quality and reduce costs. One definition of an ACO is

[a] health care organization composed of doctors, hospitals, and other health care providers who voluntarily come together to provide coordinated care and agree to be held accountable for the overall costs and quality of care for an assigned population of patients. The payment model ties provider reimbursements to performance on quality measures and reductions in the total cost of care. Under an ACO arrangement, providers in the ACO agree to take financial risk and are eligible for a share of the savings achieved through improved care delivery provided they achieve quality and spending targets negotiated between the ACO and the payer. ${ }^{12}$

There are various ACO models, ranging from those created by CMS (e.g., Pioneer ACOs) to those created by private health plans (e.g., the Cigna ACO). As of March 2015, there were an estimated 744 ACOs in the United States, with over 1,000 contracts covering 23 million people. The contracts were evenly split between public and private payers. ${ }^{22}$ The largest private insurers are rapidly increasing the number of ACOs with which they have negotiated value-based contracts. In 2015, approximately one-quarter of both UnitedHealthcare and Aetna claims payments were made under these contracts, and both insurers intend to substantially increase this share in the next few years. ${ }^{23}$

ACO providers are eligible for a share of the savings achieved through improved care delivery, conditional on meeting quality and spending targets negotiated between the ACO partners and the payer. Some ACO arrangements also include a shared-risk component wherein the ACO is at risk for at least a portion of the costs if actual spending is in excess of the spending target. A 2014 study found that just over half of programs had a contract with a private payer and that these contracts were more likely to include shared risk than Medicare contracts. ${ }^{24}$ Most of the remaining programs negotiated changes in fee schedules, such as care coordination fees. Here are some examples of the different financial incentives in ACO contracts with payers:

- CMS's Physician Group Practice demonstration-one of the earliest examples of the ACO concept-set targeted riskadjusted expenditures based on the rate of growth of costs in the local community. If per capita costs were more than 2 percent below the target level for the area, participating physician groups could earn up to 80 percent of the savings they generated.

- The Blue Shield of California_California Public Employees' Retirement System ACO pilot had a shared savings component based on zero growth in health care costs in the first year; the ACO would share savings with the payer if health care costs were below the targeted amount and would also share expenses in excess of the target.

- CIGNA's ACO model incorporates a care coordination fee that is paid to practices at the beginning of the year. At year's end, if the trend in a practice's total medical cost has improved at least 2 percentage points relative to a comparison group and quality has also improved, the care coordination fee is increased for the next year.

- The Blue Cross Blue Shield of Massachusetts Alternative Quality Contract (AQC) ACO model pays its provider groups a portion of the difference between a global budget negotiated with the payer and total medical spending and also provides a bonus of up to 10 percent above the global budget based on performance on quality measures. 
Evaluations of the effectiveness of ACOs are beginning to emerge. Recent evaluations of ACO models, which used a range of methods, have found cost savings. An evaluation of the Blue Cross Blue Shield AQC model found savings of 1.9 percent on medical services in the first year and 3.3 percent in the second year, compared with a control group of non-ACO providers. ${ }^{25}$ Over a fouryear period, these savings averaged $\$ 62.21$ per member per quarter when compared with a control group, most of which came from savings in outpatient spending. ${ }^{26}$ The ACO achieved these savings by shifting procedures, tests, and imaging to facilities with lower fees and by reducing utilization for some patients. The savings spilled over to other patients seen by the ACO providers; savings for their Medicare patients in the second year were 3.4 percent, even though the incentive payments applied only to Blue Cross Blue Shield patients. ${ }^{27}$ Costs in the Blue Shield of California ACO grew at only 3 percent in each of its first two years (2010-2011), with declines in inpatient length of stay and readmission rate. ${ }^{28}$ Finally, recent evaluations found a modest decrease in health care utilization and government spending on medical services in the first two years of the Medicare Pioneer ACO demonstration. ${ }^{29,30}$ However, the cost savings were not consistently large enough for all participating ACOs to receive the financial incentives. All of these studies focus only on spending on medical services; when incentive

The early evidence suggesting that patient experience could be better in ACOs makes this new type of provider organization potentially promising for a military health plan. payments and infrastructure support are taken into account, total costs in these early years of ACO implementation may not have decreased, at least not in all cases.

Early findings on quality of care and integration of care across providers are also promising. The Blue Cross Blue Shield of Massachusetts AQC program achieved improvements in recommended chronic care management. ${ }^{26}$ Another evaluation focusing on multiple payers in three states found increased performance on five process-of-care measures but no improvement in average blood sugar levels for patients with diabetes. ${ }^{31}$ One study, which lacked a comparison group, found increased performance on measures of diabetes, heart failure, and coronary artery disease. ${ }^{32}$ Patient experience surveys revealed that patients attributed to Medicare ACOs had higher increases in ratings of timely access to care and in how informed their primary care physicians were about care that their patients received from specialists, compared with beneficiaries not in ACOs. The subset of patients in this study with multiple chronic conditions who were in the ACOs also had higher increases in ratings of overall care. ${ }^{33}$

The early evidence suggesting that patient experience could be better in ACOs makes this new type of provider organization potentially promising for a military health plan. Active-duty beneficiaries move every few years, and beneficiaries in all groups have experience with "one-stop shopping” for health care in the MTFs. To the extent that ACOs prove able to integrate care across primary care providers and specialists, they may be easier to navigate for beneficiaries who must rely on civilian providers for their care. Roughly three-quarters of the beneficiaries living in a metropolitan 
area without an MTF live in an area that had at least one Medicare ACO in 2015.

\section{Value-Based Insurance Design}

To complement these innovations targeting health care providers, value-based insurance design targets patient behavior by structuring cost-sharing and other insurance design elements to encourage the use of high-value health services. Cost-sharing is reduced or even eliminated for services for which there is evidence of costeffectiveness and may be increased for ineffective services. This approach is in its infancy, and it is unclear whether it will prove effective in improving health outcomes and/or reducing costs. Private health plans have some experience with value-based insurance design, especially for pharmaceuticals, where lower patient cost for drugs used to treat chronic disease may improve adherence but has unknown effects on other outcomes. ${ }^{34}$ A Medicare Advantage Plan test will begin in 2017 in seven states and will contribute valuable evidence on the cost-effectiveness of this approach.

$\$$ This estimate is based on the list of 452 ACOs participating in Medicare's Pioneer, Advance Payment, and Shared Savings programs in 2015. We matched each ACO to a single metropolitan statistical area (MSA) and estimated the number of TRICARE beneficiaries in the MSA from the 2009-2013 American Community Survey. Our estimates do not account for the TRICARE population in micropolitan statistical areas with ACOs, some of which include sizable military populations (e.g., Watertown-Fort Drum, New York). Taking into account that there are ACOs that contract only with private insurers and that there are 116 new Medicare ACOs scheduled to begin in 2016, the percentage of beneficiaries with access to a Medicare ACO could be even higher.

\section{Should TRICARE Adopt These Civilian Health Plan Innovations Now?}

As we described above, models of value-based purchasing and value-based insurance design are still relatively new. It will take some time for health care providers to adapt their organizations, care delivery practices, and information technology to fully respond to the incentives they now face under value-based arrangements. More experience and research will be needed to determine whether these models lead to more cost-effective care.

DoD will want to take advantage of new provider organizations and contracting approaches that do prove to be cost-effective. However, over its 30-year history, the current TRICARE program has not had the flexibility to respond to changes in the health care system that private insurers or even Medicare have had. To avoid committing to a new approach now that falls short (as managed care did), DoD would need to wait to adopt innovative approaches in purchasing care until payers and providers converge on arrangements that improve on TRICARE's current fee-for-service approach. An alternative to waiting is to rely on private health plans for beneficiaries without MTF access instead of continuing a DoD-specific plan. The private health plans face fewer constraints in adopting innovative approaches than TRICARE has faced.

\section{Two Options for TRICARE Reform}

Two options for reforming TRICARE have been proposed in the past year. They differ in the roles they envision for both private health plans and the MTFs. Neither proposal explicitly addresses value-based purchasing. In this section, we briefly summarize these proposals. In the following section, we then raise a third option, 
which combines aspects of the two current proposals with an eye on value-based purchasing.

The first TRICARE reform proposal, advanced by MCRMC in 2015, would replace TRICARE with a menu of private insurance plans for all non-active-duty beneficiaries. These beneficiaries would still be allowed to seek care at MTFs if they choose, and the health plans would reimburse MTFs for the care provided to plan enrollees. Unspecified reimbursement and, possibly, cost-sharing approaches would be developed to encourage utilization of the MTFs. Finally, to help active-duty members cover the private plan costs for their dependents, the MCRMC recommended establishing a new pre-tax cash benefit, the basic allowance for health care. MCRMC listed a number of shortcomings in TRICARE in arguing for a shift to private health plans. These included the following:

- limited infusion of new ideas from the private sector to control costs and enhance quality

- an unresponsive referral process for specialty care in TRICARE Prime

- an inadequate civilian provider network that is not welltailored to local health care market conditions

- a complex and lengthy process of awarding the managed care support contracts, characterized by frequent challenges to award decisions and transition problems when contractors change

- high program administration costs.

The MCRMC proposal does not address in any detail how MTFs would function if non-active-duty beneficiaries were covered by private health plans. Making the MTFs reliant on private health plan reimbursement could risk their ability to attract the patients needed to sustain the skills of military medical personnel. How care provided using both military and civilian providers would be integrated is unclear, and, therefore, the implications for access, quality, and cost are uncertain.

The second reform option comes from DoD, which has included a proposal for TRICARE reform in its last three budget requests. Its current proposal, broadly described in the FY 2017 budget, proposes more-modest changes to the current TRICARE structure. The HMO (TRICARE Prime) would be replaced by an MTF-based managed care plan; the option to enroll with a civilian primary care provider in a managed care plan would be eliminated. Beneficiaries who prefer civilian care and those who live in an area without an MTF would access civilian providers through the unmanaged PPO plan. MTF care would continue to be free of charge, but the proposal includes complex changes in other beneficiary cost-sharing provisions. In particular, cost-sharing for care provided by network providers would be updated to be similar to the tiered copay schedule common in civilian employer plans. Except for dependents of junior enlisted personnel, the family-level deductible would be $\$ 600$, and the cost per visit would be $\$ 15$ to $\$ 25$ for primary care and $\$ 25$ to $\$ 35$ for specialty care, depending on beneficiary category. The changes in cost-sharing are designed to remain affordable while somewhat increasing the incentives for beneficiaries to enroll in the MTF-based plan and use the lowestcost source of care appropriate for their needs in the PPO.

This DoD proposal retains the basic structure of TRICARE as a uniquely designed military health benefit that purchases civilian care through managed care support contractors. It simplifies the enrollment options to an MTF HMO-like plan and a civilian PPO plan, and it uses tiered premiums and cost-sharing to influence 
beneficiary decisions about which plan to choose and where to get care. The DoD proposal promises innovations in MTF care, but it does not mention shifting authority and accountability for MTF enrollees' civilian care from the managed support contractors to the MTFs - a necessary step for the MTFs to function as ACOs. At the same time, keeping a "custom" plan for beneficiaries who rely on civilian providers does not address the concerns raised by the MCRMC about network adequacy and administrative efficiency. It also precludes offering military beneficiaries access to leading civilian integrated provider organizations.

\section{A New Hybrid Option: A Partial Shift to Private Health Plans}

The third option would combine elements of the two existing proposals in ways that could facilitate value-based purchasing. Similar to the DoD proposal described above, this option would replace the current TRICARE plans with a new program that offers most beneficiaries a choice of MTF-based or civilian health plans. It differs in a few important ways: It redesigns the MTF plan along ACO lines, substitutes private health plans for the civilian plan DoD envisions, and establishes a network of specialty MTF-based centers of excellence to treat beneficiaries enrolled in either type of plan.

In areas with no MTF or an MTF capable of little more than active-duty care (e.g., the Air Force clinic in Los Angeles), only private plans would be offered. In areas with an MTF capable of providing primary care and providing or managing specialty care for an enrolled population of non-active-duty beneficiaries, an MTF-based plan would be offered along with one or more private health plans. This approach differs from the approach proposed by the MCRMC because it retains an MTF-based health plan instead
The DoD proposal promises innovations in MTF care, but it does not mention shifting authority and accountability for MTF enrollees' civilian care from the managed support contractors to the MTFs-a necessary step for the MTFs to function as ACOs.

of moving all non-active-duty beneficiaries to private health plans and making the MTFs reliant for funding on reimbursements from these plans. MTFs, especially the ones with extensive specialty services, could accept reimbursement from private plans to treat their military enrollees, but this revenue stream would be in addition to a direct allocation for their enrollees.

Another component of this TRICARE reform plan would be the creation of MTF centers of excellence for specialized care that foster and sustain the operational medical skills of military specialists. Given the volume considered necessary for quality care, these centers would be established only at the largest MTFs and not at all MTFs currently designated as medical centers. These centers would provide care for all military beneficiaries, following the model of the Employer Centers of Excellence Network established by the Pacific Business Group on Health (PBGH). ${ }^{35}$ On behalf of its member employers, PBGH selects high-quality providers for highcost surgical procedures, negotiates bundled payments for specific procedures, and assists the employers in encouraging use of the 


\section{In thinking about how to reform military health benefits, it is important to take into account the frequent moves of active-duty families. Many families may prefer to keep the same plan when they move.}

selected providers. Highly specialized care not related to readiness could be directed where possible to civilian centers of excellence in the private sector or the U.S. Department of Veterans Affairs or to civilian specialists. As necessary to achieve the right number and mix of patients to sustain key medical provider skills, the MTF centers would treat non-TRICARE patients (military retired patients over age 65 , veterans, and others, potentially including civilians). The MTF centers would also manage the partnerships with civilian trauma centers developed over the past 20 years to enhance trauma skills of military providers (physicians and others) and develop opportunities for assignment of military medical personnel to civilian positions. ${ }^{36}$

The following sections discuss issues related to the design of the plan options for non-MTF areas and MTF areas, followed by the design of cost-sharing provisions in the plan options.

I An employer health plan enrollee who gets care at the selected centers has his or her cost-sharing waived, has his or her travel to the centers paid for, and has access to a patient advocate to help with making arrangements for the surgery and returning to the usual provider.

\section{The MTF Plan}

In MTF catchment areas where the beneficiary population substantially exceeds MTF capacity, beneficiaries would choose between an MTF-based plan and private health plans. Each MTF would manage its enrolled population, similar to how TRICARE Prime operates today but with a shift in accountability from the support care contractors to the MTFs for identifying community provider partners and managing civilian care for patients enrolled with the MTFs. The MTFs would report to the Army, Navy, and Air Force medical departments or the Defense Health Agency, generally consistent with the current military health organization, and they would be responsible for the costs of all care provided to their enrollees. The current managed care support contracts would be substantially redesigned to provide only the support services needed to operate the MTF plan. ${ }^{* *}$ Importantly, similar to an ACO, the MTFs would report performance data on their enrollees' quality of care, cost of care, and patient experience across all providers and have performance-based incentives. To facilitate comparison, the performance reports would employ a common set of measures chosen based on the measures resulting from the collaboration between Medicare and private insurers. Additional measures would

\footnotetext{
** The current managed care support contractors are responsible for establishing the TRICARE network, enrolling beneficiaries, directing referrals to civilian network providers, medical management of care provided by network providers, claims processing, and related customer service. Under the new MTF plan, support services could be provided by contractors, but the MTFs would assume responsibility for the key activities related to managing their enrollees: overseeing the local network of civilian providers, medical management, and referrals.
} 
need to be added to fully reflect the health care needs of the military population.

The MTF-based plan proposed here is generally similar to the Catchment Area Management (CAM) demonstration project, which was conducted in 1989-1993 along with the CHAMPUS Reform Initiative demonstration project that tested the approach ultimately adopted for TRICARE. CAM was a limited program with mixed outcomes, but it provided some useful evidence on the feasibility of an MTF-based health plan. CAM was implemented at five MTFs and, in theory, allowed MTF commanders control over all health care resources in their catchment areas. Control levels were lower than anticipated, but several of the MTFs were able to shift some care from civilian providers to the MTF. ${ }^{37}$ All five MTFs were able to develop a local network of civilian providers. Initial cost outcomes varied. Thirty years later, the MTFs are much better positioned to more actively manage all the care for their enrolled beneficiaries. In particular, MTF commanders have significantly better and timelier information on their enrollees' health care use and health status, as well as experience using the information, and DoD has eliminated the funding silos that proved problematic in CAM.

Enrollment in the MTF plan would be limited to active-duty personnel and the number of other beneficiaries that MTF-based primary care providers could accommodate. Very few MTFs have the primary care capacity to enroll all the beneficiaries in their catchment areas who rely on TRICARE for their care. Therefore, beneficiaries in many or even all MTF areas would be able to choose between the local MTF plan and one or more private health plans. To ensure that the MTFs have a sufficient number of patients, beneficiary premium contributions and/or cost-sharing for care can be set differentially for the MTF and private sector plans.

In thinking about how to reform military health benefits, it is important to take into account the frequent moves of active-duty families. Many families may prefer to keep the same plan when they move. These families would be able to choose the MTF plan or a nationwide private sector plan. Because active-duty personnel would continue to get their care primarily at MTFs, it is likely that many dependents would choose the MTF plan. In contrast, neither retired military families nor reserve families move as often. These families-currently 69 percent of the non-active-duty beneficiaries enrolled in a TRICARE option-would be more likely to choose high-quality local plans where these can be offered alongside MTF and nationwide plans.

The MTF plan could be reimbursed on a capitated basis (risk-adjusted payment) for each enrolled beneficiary and receive prospective or retrospective payments, as appropriate, for services provided to non-MTF enrollees. Active-duty care and readiness activities would be funded separately from a medical readiness account, either contained in the service budgets or consolidated in the current Defense Health Program budget, which would also fund the premium payments for non-active-duty beneficiaries enrolled in MTF and private plans. When uniformed MTF providers shift time that was previously used for non-active-duty patient care to military activities instead, including training and deployment, the MTF plan would receive additional funding from the readiness account to replace lost MTF capacity by adding nonmilitary staff or purchasing more care in the community. Alternatively, the MTF plan could reimburse the services for the military manpower used for non-active-duty patient care, thus ensuring 
that resources are immediately available to replace unavailable manpower. ${ }^{38}$

Beneficiary premiums and cost-sharing might be set lower in the MTF plan to ensure that the MTFs' capacity is fully utilized. This would replace the current policy that gives the MTFs right of first refusal for Prime enrollment. Opening the MTFs to competition from private health plans, even if the MTF plan were more attractive financially, incurs a risk that some MTFs may not attract enough enrollees. If an MTF does not receive sufficient funding to cover its costs from the MTF plan, its military service would have to cover the shortfall. Over time, the competition should strengthen lower-performing MTFs, and beneficiaries would gain from not being required to use MTFs they did not perceive as offering good value.

In areas where there is a suitable ACO, MTFs with limited or no specialty capability may be able, over time, to affiliate with the ACO to take advantage of its specialty network and integrated care mechanisms, including case management and information systems. We estimate that roughly 40 percent of TRICARE beneficiaries live in an area that has both an MTF and an ACO; about half of them are in an area with a military hospital, and half are in an area served only by a military clinic.

\section{Private Health Plans}

Reflecting the pace of innovation in the civilian health sector and the growing complexity of health plan design and operations, this option would replace a DoD-specific plan with a choice of private health plan. The non-MTF-area plan options could include preexisting high-value regional plans in areas where the beneficiary population is sufficiently large to make the effort to select such plans. The regional plans would be chosen using value-based purchasing criteria-i.e., based on their performance (quality of care; patient experience, including access; and cost)—and with a preference for plans that contract with successful ACOs or other integrated provider organizations. An estimated two-thirds of TRICARE beneficiaries live in an area with at least one Medicare ACO; one-third of them also are in the catchment area of a military hospital offering specialty care..$^{\dagger \dagger}$ Finally, the options would include one or more national plans from large insurers.

Unlike the Federal Employees Health Benefit Program, under this option DoD should select a limited number of high-value health plans to make health plan choice tractable. Selection criteria would be tailored according to the needs of military beneficiariese.g., especially in areas with a sizable active-duty family population, support for finding appropriate providers in plan networks could be included in the criteria. The right selection criteria should allow DoD to offer its beneficiaries, for the first time, some plans that are highly regarded and rely on integrated delivery systems (such as Kaiser Permanente, Geisinger Health System, and Scott \& White) that active-duty family members may find easier to navigate. Note, however, that beneficiaries who prefer to keep the same health plan if they move could also choose the national plan if it is offered in all areas or the MTF plan for those moving between military installations.

$\dagger \dagger$ These estimates are based on data from the 2009-2013 American Community Survey, merged with hospital information from the 2013 American Hospital Association annual survey and physician data from the 2013 SK\&A physician database. 
Both the regional and national non-MTF plans could direct beneficiaries to MTF centers of excellence for complex surgical care related to maintaining military physician skills relevant for wartime (e.g., vascular surgery) and reimburse the MTFs for the care provided. DoD would need to cover patient (and accompanying family member) travel costs if referral to the military centers were made mandatory. DoD's electronic health record system would support care integration for MTF-plan enrollees who are treated in centers of excellence. DoD plans to begin implementing a new system at the end of this year. A key criterion in awarding the contract was interoperability with civilian providers' electronic health record systems. In future years, the ability to integrate care between military and civilian providers should increase, although it will likely remain more limited than for patients treated entirely within the MTF system.

\section{Beneficiary Cost-Sharing Changes}

TRICARE Prime premium contributions and copays have changed little since the plan was introduced in 1996. Numerous assessments have concluded that TRICARE needs more robust and betterdesigned beneficiary cost-sharing provisions, ${ }^{39,40}$ and DoD has proposed changes, including retiree premium increases, on several occasions. ${ }^{\ddagger}$ The failure to adjust TRICARE Prime cost-sharing over time to keep up with inflation and costs in employer health plans has well-known consequences: high beneficiary care utiliza-

抹 The FY 2017 President's Budget Request proposed a four-year increase in the TRICARE Prime retiree premium. Family coverage in FY 2018 would have been set at 4 percent of the retiree's gross military retirement income and ranged from $\$ 594$ to $\$ 1,226$ (up to $\$ 1,840$ for flag officers).
Cost-sharing has increased substantially in employer plans over time. In 2015, 81 percent of employees had a plan with a deductible, and over 90 percent had some form of copayment or cost-sharing for care.

tion relative to civilians and a high number of retiree participants who transferred from their employer plans to TRICARE after TRICARE was implemented. After 20 years, the adjustments to premium contributions needed to induce retirees to shift back to employer coverage would be impractically large. Therefore, most past proposals have focused on increasing the share of plan costs that retirees pay to what they were when TRICARE was implemented.

Cost-sharing has increased substantially in employer plans over time. In 2015, 81 percent of employees had a plan with a deductible, and over 90 percent had some form of copayment or cost-sharing for care. ${ }^{5}$ Notably, the average annual family-level deductible in plans with a deductible was over $\$ 4,000$, and the average cost per visit was $\$ 24$ for primary care and $\$ 37$ for specialty care. DoD may experience resistance among private insurers to offer a military plan with no (or very low) cost-sharing. Further, ACOs may be reluctant to assume responsibility for patients with no or low cost-sharing, as they may have little experience controlling unnecessary utilization under these circumstances. If the increases in cost-sharing included in the DoD reform proposal are implemented, they may be sufficient to allay any private insurer and ACO concerns. The lower deductibles proposed by DoD may be 
advantageous, as they pose less of a barrier for accessing appropriate care.

Differential retiree premium contributions for civilian plans and the MTF plan could be based on value-i.e., plan cost and a limited set of quality measures reflecting quality of care and health outcomes. DoD could set the beneficiary contribution for the "best" plan in each area as a fixed percentage of the average cost of all such plans nationally or a fixed percentage of military retirement pay. Civilian plans with a higher total premium cost could have a beneficiary premium differential equal to some or all of the higher cost and dependent on measured quality outcomes, if available. Beneficiaries would be provided with information on the choices available to them in each location, modeled on the information provided by CMS for Medicare Advantage plans; CMS developed its plan information based on extensive research on what beneficiaries want to know and how they respond to information. ${ }^{41}$

The premium contribution for the MTF plan (and the DoD payment to the plan per enrollee) may be difficult to set initially, in light of the complex mission and funding streams for MTFs and data limitations. In this case, the MTF plan premium contribution and DoD payment could be based on the beneficiary and DoD premium contributions for civilian plans. Over time, the MTF plan premium contribution could be adjusted as necessary so that enough beneficiaries choose the MTF plan in each area to fill its capacity (just as recruiting bonuses are adjusted to meet enlistment goals, for example). This would avoid shortfalls in funding for MTFs that fail to meet their enrollment goals (which the military services would have to cover) and also provide a ready measure of the value that MTFs are providing relative to civilian plans. Allocating some or all of the financial risk associated with lower beneficiary premiums for low-performing MTFs with the military services could strengthen the MTFs' performance-based incentives.

It would take considerable time to plan and implement the elements required for this third option for reforming military health care, especially in MTF areas; setting up the MTF plan envisioned in this option would include revising the funding streams for medical readiness and care provided to MTF plan enrollees, determining the private plans to be offered, and setting the DoD and beneficiary premium payments for the MTF versus private plans. In contrast, moving to private health plans in non-MTF areas could probably be accomplished over the next few years as the current managed care support contracts end. However, before committing to a strategy relying on private health plans, DoD should compare the costs and health outcomes for military beneficiaries currently relying on TRICARE and using civilian providers with costs and outcomes for comparable beneficiaries in private health plans.

\section{Military Health Benefits Advisory Commission}

Finally, Congress or DoD may want to consider establishing a Military Health Benefits Advisory Commission to provide analysis and advice on the DoD health benefit during this period of change. This commission could be modeled on the Medicare Payment Advisory Commission (MedPAC) and the Medicare Evidence Development \& Coverage Advisory Committee (MEDCAC). This advisory group would include leading experts on health plan design and provider reimbursement and would complement the Defense Health Board, which focuses primarily on other issues in military medicine. 


\section{Summary}

The design of TRICARE was based on managed care plans common at the time of its creation. The civilian health insurance market has largely moved away from this design and is increasingly using value-based purchasing and value-based insurance design to strengthen incentives for high-quality, efficient health care. In this Perspective, we described models of value-based purchasing and value-based insurance design and explained how TRICARE might be replaced by contracting approaches that take advantage of the innovations being implemented in civilian health insurance while preserving the capability of MTFs to maintain medical readiness of military personnel and the operational medical skills of military medical providers. To achieve balanced objectives, the hybrid approach outlined here blends aspects of two existing proposals by retaining an MTF-centric health plan that has been reorganized to incorporate features of an ACO but shifting to private health plans for beneficiaries who will rely primarily on civilian providers for their care.

Finally, regardless of the approach that TRICARE reform takes, it should facilitate and incentivize integrated, accountable care for $\mathrm{DoD}$ beneficiaries served by the MTFs. The MTFs play a critical role in sustaining the active-duty medical force, which supports the primary missions of the Military Health Systemmedical readiness of military personnel and medical support of military operations. Changes to TRICARE need to sustain the MTF capabilities and promote the integration of care for these beneficiaries who must use both MTF and civilian providers. 


\section{References}

${ }^{1}$ Department of Defense, Military Health System Review: Final Report to the Secretary of Defense, 2014. As of March 10, 2016: http://www.health.mil/ Military-Health-Topics/Access-Cost-Quality-and-Safety/MHS-Review

${ }^{2}$ Military Compensation and Retirement Modernization Commission, Final Report, 2015. As of January 20, 2016: http://mldc.whs.mil/reports\#final

${ }^{3}$ Glied, S., "Managed Care," in A. J. Culyer and J. P. Newhouse, Handbook of Health Economics, Vol. 1, Elsevier Science B.V., 2000.

${ }^{4}$ Department of Defense, Evaluation of the TRICARE Program: Access, Cost, and Quality; Fiscal Year 2015 Report to Congress, 2015.

${ }^{5}$ Kaiser Family Foundation and Health Research and Educational Trust, Employer Health Benefits: 2015 Annual Survey, 2015. As of February 22, 2016:

http://files.kff.org/attachment/report-2015-employer-health-benefits-survey

${ }^{6}$ Agency for Healthcare Research and Quality, Evaluating the Impact of ValueBased Purchasing: A Guide for Purchasers, 2002. As of January 13, 2016: http://archive.ahrq.gov/professionals/quality-patient-safety/quality-resources/ value/valuebased/evalvbp1.html

${ }^{7}$ Maio, V., C. W. Hartmann, N. I. Goldfarb, A. R. Roumm, and D. B. Nash, "Are Employers Pursuing Value-Based Purchasing?” Benefits Quarterly, Vol. 21, No. 3, 2005, pp. 20-29.

${ }^{8}$ National Business Coalition on Health, Value-Based Purchasing: A Definition, 2011. As of January 13, 2016: http://www.nbch.org/Value-based-Purchasing-A-Definition

${ }^{9}$ Dafny, L. "Hospital Industry Consolidation-Still More to Come?" New England Journal of Medicine, Vol. 370, No. 3, January 16, 2014, pp. 198-199.

${ }^{10}$ Cutler, D. M., and M. F. Scott, "Hospitals, Market Share, and Consolidation," JAMA, Vol. 310, No. 18, 2013, pp. 1964-1970.

${ }^{11}$ Hwang, W., J. Chang, M. LaClare, and H. Paz, "Effects of Integrated Delivery System on Cost and Quality," American Journal of Managed Care, Vol. 19, No. 5 , May 1, 2013, pp. e175-e184.

${ }^{12}$ Damberg, C. L., M. E. Sorbero, S. L. Lovejoy, G. R. Martsolf, L. Raaen, and D. Mandel, Measuring Success in Health Care Value-Based Purchasing Programs: Findings from an Environmental Scan, Literature Review, and Expert Panel Discussions, Santa Monica, Calif.: RAND Corporation, RR-306-ASPE, 2014. As of January 25, 2016: http://www.rand.org/pubs/research_reports/RR306.html
${ }^{13}$ CMS, CMS Quality Measure Development Plan: Supporting the Transition to the Merit-Based Incentive Payment System (MIPS) and Alternative Payment Models (APMs) (DRAFT), 2015. As of March 4, 2016: https://www.cms.gov/Medicare/ Quality-Initiatives-Patient-Assessment-Instruments/Value-Based-Programs/ MACRA-MIPS-and-APMs/

Draft-CMS-Quality-Measure-Development-Plan-MDP.pdf

${ }^{14}$ Ryan A., M. Sutton, and T. Doran, "Does Winning a Pay-for-Performance Bonus Improve Subsequent Quality Performance? Evidence From the Hospital Quality Incentive Demonstration," Health Services Research, Vol. 49, No. 2, 2014, pp. 568-587.

${ }^{15}$ Benzer, J. K., G. J. Young, J. F. Burgess, Jr., E. Baker, D. C. Mohr, M. P. Charns, and P. J. Kaboli, "Sustainability of Quality Improvement Following Removal of Pay-for-Performance Incentives," Journal of General Internal Medicine, Vol. 29, No. 1, January 2014, pp. 127-132.

${ }^{16}$ Ryan, A. M., J. F. Burgess, Jr., M. F. Pesko, W. B. Borden, and J. B. Dimick, "The Early Effects of Medicare's Mandatory Hospital Pay-for-Performance Program," Health Services Research, Vol. 50, No. 1, February 2015, pp. 81-97.

${ }^{17}$ Fagan, P. J., A. B. Schuster, C. Boyd, J. A. Marsteller, M. Griswold, S. M. Murphy, L. Dunbar, and C. B. Forrest, "Chronic Care Improvement in Primary Care: Evaluation of an Integrated Pay-for-Performance and Practice-Based Care Coordination Program Among Elderly Patients with Diabetes," Health Services Research, Vol. 45, No. 6, December 2010, pp. 1763-1782.

${ }^{18}$ Rosenthal, M. B., Z. Li, D. Robertson, and A. Milstein, "Impact of Financial Incentives for Prenatal Care on Birth Outcomes and Spending," Health Services Research, Vol. 44, No. 5, 2009, pp. 1465-1479.

${ }^{19}$ Kruse, G. B., D. Polsky, E. A. Stuart, and R. M. Werner, "The Impact of Hospital Pay-for-Performance on Hospital and Medicare Costs," Health Services Research, Vol. 47, No. 6, December 2012, pp. 2118-2136.

${ }^{20}$ Hussey, P. S., A. W. Mulcahy, C. Schnyer, and E. C. Schneider, Bundled Payment: Effects on Health Care Spending and Quality, Agency for Healthcare Research and Quality, 2012. As of January 25, 2016: http://www.ahrq.gov/ research/findings/evidence-based-reports/gapbundtp.htm

${ }^{21}$ Kivlahan, C., J. M. Orlowski, J. Pearce, J. Walradt, M. Baker, and D. G. Kirch, "Taking Risk: Early Results from Teaching Hospitals' Participation in the Center for Medicare and Medicaid Innovation Bundled Payments for Care Improvement Initiative," Academic Medicine, February 16, 2016. As of April 13, 2016: http:// journals.lww.com/academicmedicine/Abstract/publishahead/ Taking_Risk__Early_Results_From_Teaching.98567.aspx 
${ }^{22} \mathrm{Tu}$, T., D. Muhlestein, S. L. Kocot, and R. White, Origins and Future of Accountable Care Organizations, Washington, D.C.: Brookings Institution, 2015. As of January 14, 2016: http://www.brookings.edu/research/ papers/2015/05/12-origins-and-future-of-accountable-care-aco

${ }^{23}$ Japsen, B., "Health Insurers Poised to Profit on Value-Based Care," The Motley Fool, March 4, 2015.

${ }^{24}$ Lewis, V. A, C. H. Colla, W. L. Schpero, S. M. Shortell, and E. S. Fisher, "ACO Contracting with Private and Public Payers: A Baseline Comparative Analysis," American Journal of Managed Care, Vol. 20, No. 12, December 12, 2014 , pp. 1008-1014.

${ }^{25}$ Song, Z., D. G. Safran, B. E. Landon, M. B. Landrum, Y. He, R. E. Mechanic, M. P. Day, and M. E. Chernew, “The 'Alternative Quality Contract,' Based on a Global Budget, Lowered Medical Spending and Improved Quality," Health Affairs, Vol. 31, No. 8, August 2012, pp. 1885-1894.

${ }^{26}$ Song, Z., S. Rose, D. G. Safran, B. E. Landon, M. P. Day, and Michael E. Chernew, "Changes in Health Care Spending and Quality 4 Years Into Global Payment," New England Journal of Medicine, Vol. 371, No. 18, October 30, 2014, pp. $1704-1714$

${ }^{27}$ McWilliams, J. M., B. E. Landon, and M. E. Chernew, "Changes in Health Care Spending and Quality for Medicare Beneficiaries Associated with a Commercial ACO Contract," JAMA, Vol. 310, No. 8, 2013, pp. 829-836.

${ }^{28}$ Markovich, P., "A Global Budget Pilot Project Among Provider Partners and Blue Shield of California Led to Savings in First Two Years," Health Affairs, Vol. 31, No. 9, 2012, pp. 1969-1976.

${ }^{29}$ Schwartz, A. L., M. E. Chernew, B. E. Landon, and J. M. McWilliams, "Changes in Low-Value Services in Year 1 of the Medicare Pioneer Accountable Care Organization Program," JAMA Internal Medicine, Vol. 175, No. 11, November 2015, pp. 1815-1825.

${ }^{30}$ McWilliams, J. M., M. E. Chernew, B. E. Landon, and A. L. Schwartz, "Performance Differences in Year 1 of Pioneer Accountable Care Organizations, New England Journal of Medicine, Vol. 372, 2015, pp. 1927-1936.

${ }^{31}$ Salmon, R. B., M. I. Sanderson, B. A. Walters, K. Kennedy, R. C. Flores, and A. M. Muney, "A Collaborative Accountable Care Model in Three Practices Showed Promising Early Results on Costs and Quality of Care," Health Affairs, Vol. 31, No. 11, November 2012, pp. 2379-2387.

${ }^{32}$ Sebelius, K., Physician Group Practice Evaluation: Report to Congress, Department of Health and Human Services, 2009.
${ }^{33}$ McWilliams, J. M., B. E. Landon, M. E. Chernew, and A. M. Zaslavsky, "Changes in Patients' Experiences in Medicare Accountable Care Organizations," New England Journal of Medicine, Vol. 371, No. 18, October 30, 2014, pp. 1715-1724.

${ }^{34}$ Mann, B. S., L. Barnieh, K. Teng, D. J. T. Campbell, F. Clement, B. Hemmelgarn, M. Tonelli, D. Lorenzetti, and B. J. Manns, "Association Between Drug Insurance Cost Sharing Strategies and Outcomes in Patients with Chronic Diseases: A Systematic Review," PLOS One, Vol. 9, No. 3, 2014, e89168. As of March 10, 2016: http://journals.plos.org/plosone/article?id=10.1371/ journal.pone.0089168

${ }^{35}$ Pacific Business Group on Health, Employers Centers of Excellence: Negotiating High-Quality Care at Top Performing Centers, 2014. As of January 21, 2016: http://www.pbgh.org/storage/documents/ECEN_Program_Summary1214.pdf

${ }^{36}$ Eibner, C., Maintaining Military Medical Skills During Peacetime, Santa Monica, Calif.: RAND Corporation, MG-638-OSD, 2008. As of January 21, 2016: http://www.rand.org/pubs/monographs/MG638.html

${ }^{37}$ Congressional Budget Office, Managed Care in the Military: The Catchment Area Management Demonstrations, 1991. As of January 23, 2016: https://www.cbo.gov/publication/20421

${ }^{38}$ Hosek, S., and G. Cecchine, Reorganizing the Military Health System: Should There Be a Joint Command? Santa Monica, Calif.: RAND Corporation, MR1350-OSD, 2001. As of January 21, 2016: http://www.rand.org/pubs/monograph_reports/MR1350.html

${ }^{39}$ Task Force on the Future of Military Health Care, Final Report, 2007. As of January 23, 2016: http:/www.dcoe.mil/content/Navigation/Documents/ 103-06-2-Home-Task_Force_FINAL_REPORT_122007.pdf

${ }^{40}$ Congressional Budget Office, Approaches to Reducing Federal Spending on Military Health Care, 2014. As of January 23, 2016: https://www.cbo.gov/sites/default/ files/113th-congress-2013-2014/reports/44993-MilitaryHealthcare.pdf

${ }^{41}$ Centers for Medicare and Medicaid Services, "Plan Quality and Performance Ratings,” undated. As of January 22, 2016: https://www.medicare.gov/ find-a-plan/results/planresults/planratings/compare-plan-ratings.aspx?PlanType= MAPD\&AspxAutoDetectCookieSupport=1\#plan_rating_summary

${ }^{42}$ HealthCare.gov, "High Deductible Health Plan (HDHP)," undated. As of April 13, 2016: https:/www.healthcare.gov/glossary/high-deductible-health-plan/ 


\section{About This Perspective}

TRICARE, the health benefits program created for beneficiaries of the U.S. Department of Defense, covers health care provided in military treatment facilities and by civilian providers. Congress is now considering how to update TRICARE, which was first developed in the 1980s drawing on managed care concepts from civilian health plans. This Perspective places TRICARE's current managed care strategy in historical context and describes recent innovations by private insurers and Medicare intended to enhance the value-cost and quality-of the care they purchase for their members. With this movement toward value-based purchasing as background, the authors consider two existing proposals for reform and describe an alternative approach for consideration that blends the existing proposals.

The views expressed are those of the authors. The authors thank Chrissy Eibner and Mark Friedberg, who served as peer reviewers for this document.

Funding for this Perspective was provided by philanthropic contributions from RAND supporters and income from operations. The research was conducted within the Forces and Resources Policy Center of the RAND National Security Research Division (NSRD). NSRD conducts research and analysis on defense and national security topics for the U.S. and allied defense, foreign policy, homeland security, and intelligence communities and foundations and other nongovernmental organizations that support defense and national security analysis.

For more information on the RAND National Security Research Division, see www.rand.org/nsrd or contact the director (contact information is provided on the web page)

\section{About the Authors}

Susan Hosek retired from RAND as a senior economist in 2014 and is a member of RAND's adjunct research staff. Her recent research has addressed issues in military and veteran health care and the military service of gay personnel and women.

Melony Sorbero is a senior health policy researcher at RAND. Her research interests include performance measurement, value-based purchasing, quality and efficiency of health care, and delivery system innovations.

Grant Martsolf is a policy researcher at RAND. His research interests include the health care workforce, primary care, and delivery system innovations.

Ryan Kandrack is a health policy research assistant at RAND. His research interests include health care delivery and payment innovation, behavioral economics, and health care workforce issues.

\section{Limited Print and Electronic Distribution Rights}

This document and trademark(s) contained herein are protected by law. This representation of RAND intellectual property is provided for noncommercial use only. Unauthorized posting of this publication online is prohibited. Permission is given to duplicate this document for personal use only, as long as it is unaltered and complete. Permission is required from RAND to reproduce, or reuse in another form, any of our research documents for commercial use. For information on reprint and linking permissions, please visit www.rand.org/pubs/permissions.html.

The RAND Corporation is a research organization that develops solutions to public policy challenges to help make communities throughout the world safer and more secure, healthier and more prosperous. RAND is nonprofit, nonpartisan, and committed to the public interest.

RAND's publications do not necessarily reflect the opinions of its research clients and sponsors. RAND ${ }^{\circledR}$ is a registered trademark.

For more information on this publication, visit www.rand.org/t/PE195.

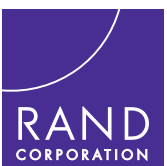

www.rand.org 